\title{
Using Service Oriented Architecture for Reconceiving Quality E Training
}

\author{
Ruchi K. Sharma \\ M.E (Computer), Sardar Patel \\ Institute of Technology (SPIT), \\ Mumbai. Assistant Professor, \\ Information Technology Department, \\ NMIMS, Mumbai, India
}

\author{
Radha Shankarmani \\ HOD, Information Technology \\ Department \\ Sardar Patel Institute of \\ Technology (SPIT), \\ Mumbai, India
}

\begin{abstract}
ELearning is a fast maturing domain that involves the integration of many technologies. Learning is a knowledge intensive domain. Recent trend is to develop software applications using service oriented architectures. However current learning systems have predefined learning modules and do not take into account the competency of learner and other behavioral aspects. This paper proposes a dynamic framework for e learning systems using web services that overcomes these drawbacks. The idea is to create value added services from set of existing learning services. The approach employed utilizes the principles of service orientation that lists the software resources required for a learner depending on his/her skills, learning capability and the requirement of the organization. It customizes the learning material to each ones need. This paper is dedicated to providing improved learning opportunities for the IT industry that meet the needs of employees and enhance their knowledge and expertise level for skills relevant to their role in the software team.
\end{abstract}

\section{General Terms}

Service oriented Architecture

\section{Keywords}

Service oriented, Web services, E learning, IT industry, skill enhancement

\section{INTRODUCTION}

With the advent of Internet, information is easily shareable across boundaries and is increasingly being used in the domain of academics.

E-Learning is defined as "the delivery of a learning, training or education program by electronic means. E-Learning involves the use of a computer or electronic device (e.g. a mobile phone) in some way to, educational or learning material as stated by Derek Stockley [1]. The scope of e learning extends not only in classrooms but also in corporate places to learn new technologies or upgrade skills.

Victor Jeurissen reported that, " $75 \%$ of CEOs think employee education is the most critical. Learning directly supports the top agenda of CEOs, business groups and customer responsiveness" (Moeng, 2004).

Global e-Learning expenditure stands at approximately $\$ 91 \mathrm{bn}$ in 2012 and is projected to grow at $23 \%$ per annum through to 2017. IBIS Capital has reviewed the global e-Learning the market to identify the changes taking place and the business opportunities therein [2] Report suggests a huge potential for emerging software technologies in this domain. However in spite of huge investment, there is an absence of software delivering the right skills and knowledge at a personalized level.

SERVICE-ORIENTED computing (SOC) enables new kinds of flexible and scalable business applications and can improve the productivity of programming and administering applications in open distributed systems [8]

W3C (World Wide Web Consortium) states Web services is "a software system designed to support interoperable machine-to-machine interaction over a network. It has an interface described in a machine-process able format (specifically WSDL). [7]

Other systems interact with the Web service in a manner prescribed by its description using SOAP-messages, typically conveyed using HTTP with an XML serialization in conjunction with other Web-related standards [6]

\section{EXISTING SYSTEMS}

\subsection{Overview}

Multiple online e- learning tools are available on the internet. Several methods in [3], [4], [5] describe usage of wireless sensor networks and context aware environment for elearning systems. Context aware ubiquitous learning defines a new stage of $e$-learning and mobile learning.

However a vast majority of these tools are web based and cannot be used across systems or devices. In paper [9], standard for the four-stage automatic composition architecture is suggested. Developers can therefore inherit classes or implement classes and interfaces in the top level as templates and for reuse, and extend them by customization for their own usage.

Information available in World Wide Web is the form of distributed and heterogeneous sources. Available tools that can help in making a good and quick selection of information we are interested in. Many of them are based on content based search taking keywords from the user. This forms the general collection of information. The system generates a kind of user independent collection of documents which are semantically similar to each other.

\subsection{Current Issues}

User is faced with information overload in current learning systems. Also, the system doesn't take any input from the user to find out whether the user need is satisfied

Some of the issues faced by consumers in current e learning systems are as follows: 
- Difference in format of content available on Internet. Hence difficult to build a standardized solution

- Increase in Server load due to storage of huge number of e-resources

- Same homogenous content fed to all e learning users

\section{METHODOLOGY}

Given the continuous evolving technologies in the Information Technology domain, the content required for training the IT practitioners and management team alike also keeps on changing at a rapid pace.

Due to this web services that can dynamically compose the most relevant technological material for a particular team member can be extremely beneficial. This can be done only after evaluating the following:

i. The current skill sets of the software team member

ii. Skills required for the particular project assigned to team member

The method for evaluating i) can be done via Web Service having a dynamic online exam set. We need to accept the user priorities first and understand what the user actually intends to learn after analyzing particular team members individual skill set.

We present to the user different forms of information as below:

(i) Skills required for the project, broad specification (probably a high level design) of the project.

(ii) Customized hyperlinks of all those documents to be read / learnt.

(iii) Technology skill based learning. Using tools is the most difficult part, and there are various issues attached to it namely compatibility, cost.

\subsection{Criteria for evaluation}

1. Selection Of Resource Material

2. Level of Understanding of developer

3. Study Prerequisites (According To Capability Of Learning)

4. Non-homogenous data source (text, templates, figures, tables, code, tools to name a few), distributed and dynamically changing.

5. Hyperlinks given to the documents it references.

\subsection{Phases}

The phases included for this system are:

1. Online Evaluation: To find current learner status

2 Assessments: In form of quiz, multiple choice question, program coding, etc

3. Resource availability: Heterogeneous metadata presented to learner at each stage

4. Feedback: Feedback on each learning module acquired from developer.

\section{WEB SERVICE COMPOSITION}

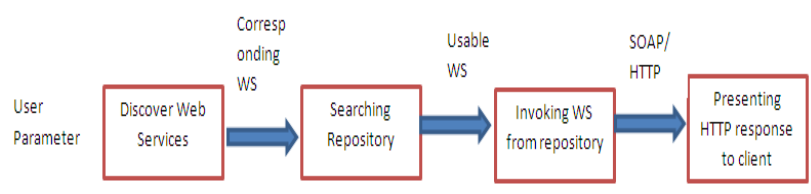

Fig. 1. Proposed System Flow diagram

The proposed Elearning system composes Web services on the fly taking minimum user input and maximizes learning efficiency in a relatively small amount of time leading to decreased training costs. For e.g. a developer needs to learn only about a particular category of a sub module he is presented with resources related to only that category.

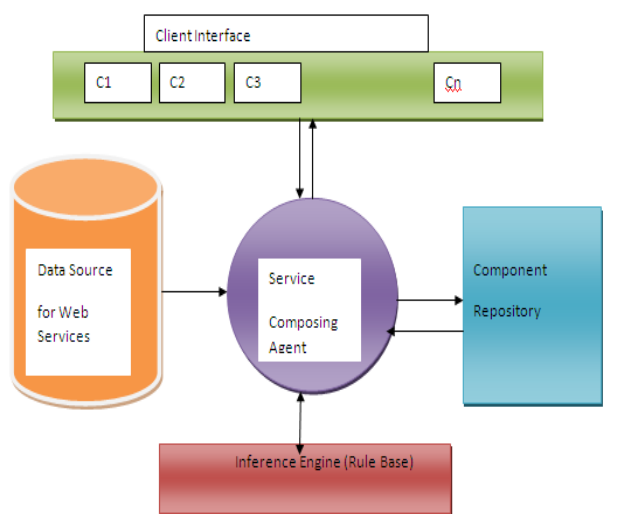

Fig. 2. System component block diagram

The significant components are as follows:

1. Client interface module:

It is a web based user interface module to create customized user profile that handles multiple client requests simultaneously.

2. Data Source for Web Services:

Stores all web services related to all elearning components in WSDL file format

3. Component repository module:

Consists of database for resources, question base and user, administrator profile information

\section{Service Composing Agent:}

It is the central component that handles entire workflow of the system. Upon receiving client requests it creates a personalized dynamic profile for each user based on minimal input parameters from learner. It then consults the inference engines which comprises of rule base storing learning rules for every user combination. Depending upon the rule output, related web services created in SOAP are extracted from component repository and HTTP response is presented to client.

The high level conceptual architecture for the proposed model is explained as in Fig. 3.Here the front end consists of web service clients $(1,2 \ldots n)$ that concurrently access the proposed software system as well as other Learning management systems (LMS) that may be integrated with the framework proposed. This is possible since content is independent of delivery due to XML course content.

Foundation web services layer are basic web services required by system Logging, Role as client or 
administrator and user authentication. The services that are considered as common for all LMS are kept in a separate layer .These are:

i. Authoring web service: Specifies the creation of digital content for a heterogeneous environment,

ii. CMS(Content Management Services): Used for updation ,deletion or other modification of data resources and

iii. Payment web service: May vary according to number of resources the client has subscribed to.

Initially the resources used by the training department are kept in the repository. The learner's needs are identified using online evaluation and other learner parameters. Further resources are added iteratively depending on learner's capability and requirement of the project. Learners of similar capability require same resources.

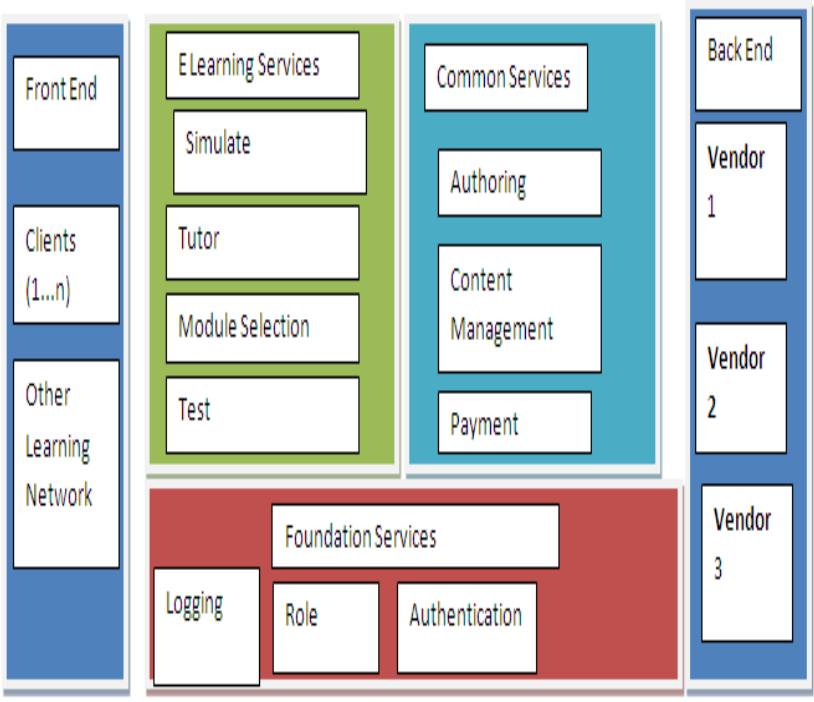

Fig. 3. High Level Conceptual Architecture

Criteria that is fulfilled for any topic for online learning:

1. Learning goals to be understood.

2. Assessment of learning and rating must be possible for the topic.

3. Course content should start from what the learner knows to provide resources.

4. Opportunities for practice sessions

5. Instant feedback to prepare checklists to use when reviewing online course.

\section{FACTORS CONSIDERED FOR SELECTING WEB SERVICES IN COMPOSITION SYSTEMS}

The issues being faced during selection of web services in service composition systems and the proposed solution for overcoming the same for elearning scenario have been described here:

\subsection{Availability:}

Service availability is a crucial success factor to be considered by the service provider while building applications in enterprise systems. Due to this if one component Web service becomes unavailable, the entire composite Web service is being available to the client, even if it is for a few seconds can lead to enormous losses
Solution: If a particular resource in the e-learning domain generated as hyperlink becomes unavailable at run time the web service will automatically redirect it to alternative URI (resources) in its place.

\subsection{Response Time:}

Web services that are have slow HTTP data request can lead to non satisfaction of clients.

Solution: Choosing external service provider carefully after monitoring Web service response times and selecting ones with least latency issues. Less reliance on $3^{\text {rd }}$ party service providers is required. Resources in form of hyperlinks can be summarized as in Table1.

Table 1. Category of E Resources presented

\begin{tabular}{|c|c|}
\hline Resource id & Category \\
\hline R1 & Less than average \\
\hline R2 & $\cdots$ \\
\hline$\ldots$ & Expert \\
\hline Rn & \\
\hline After providing additional resources for each
\end{tabular}
category, different set of learners can be made to take the test Table for scheduled training can be as given in Table2.

Table 2. Topic generation Categorization

\begin{tabular}{|c|c|}
\hline Topic & Test score level \\
\hline T1 & Low \\
\hline T2 & Average \\
\hline$\ldots$ & $\ldots$ \\
\hline $\mathrm{Tn}$ & High \\
\hline
\end{tabular}

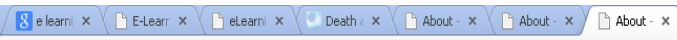

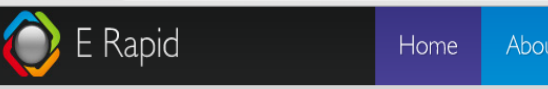

About

\section{The Team}

This web service is deroloped as a part of the ME project.

Online software training

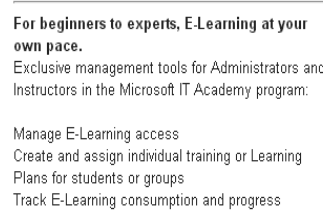

E Rapid IT Academy a Web Senvice allows you to improve your skills witt and engaging online training This site is designated to help you access and take advantage of all the available to you

aims to break the barriers to education by reaching millions of learners The

Manage E-Learning access

Plans for students or groups

Track E-Learning consumption and progress

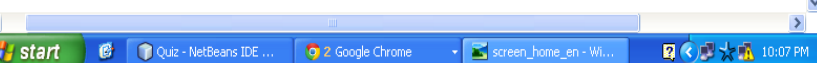

Fig. 4. Project User Interface 
Volume 94 - No 9, May 2014

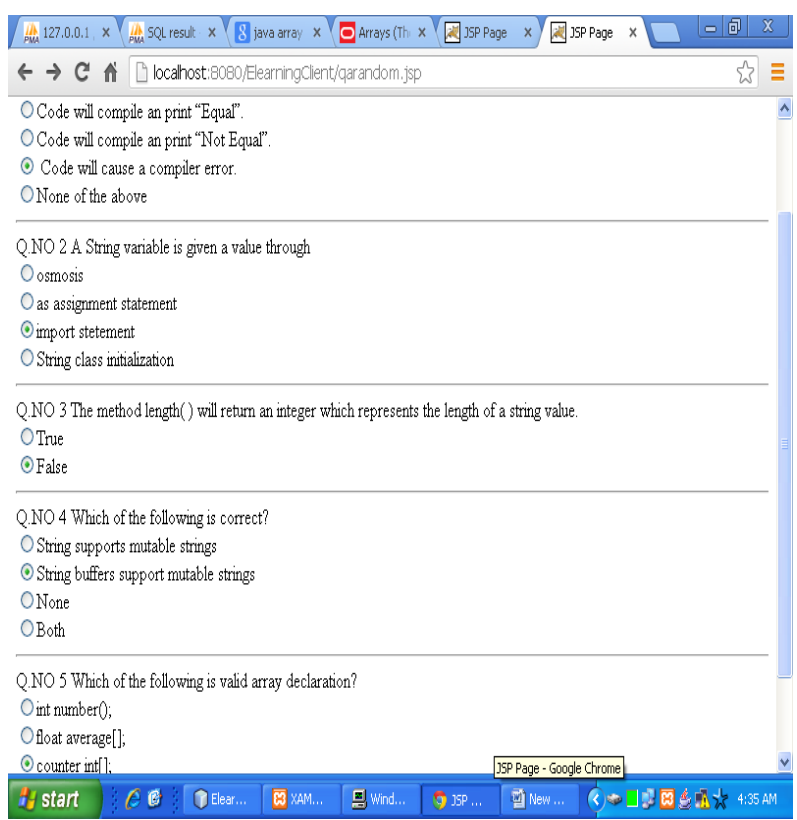

Fig. 5. Question generation based on skill level

\section{Description:}

In Figure 5,the questionnaire is presented based on online profile of the learner which consists of skills possessed by the user and skills required for project.Questionairre developed at back end is segregated into categories $\mathrm{C} 1, \mathrm{C} 2$..Cn depending on module studied by the learner

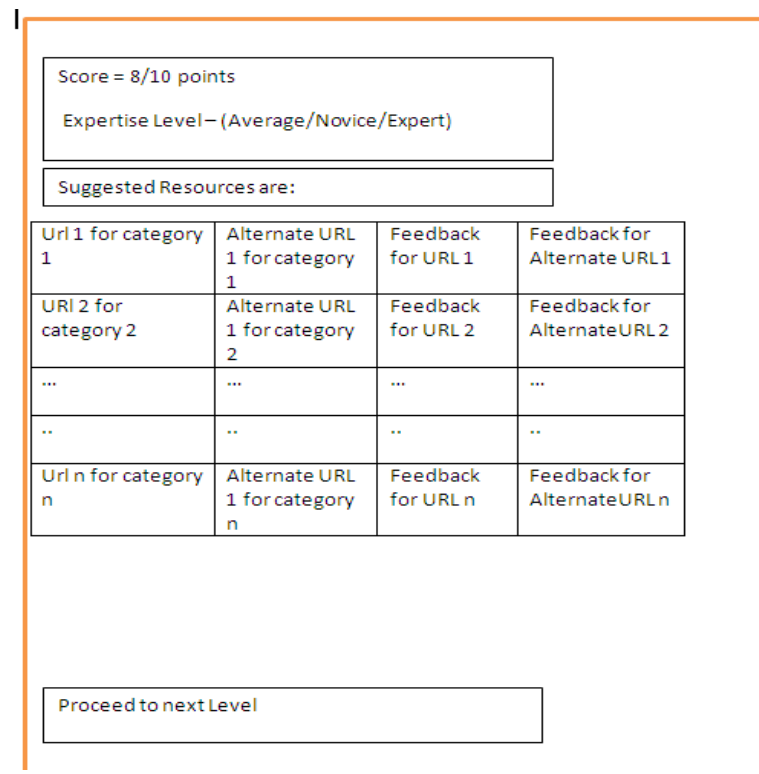

Fig. 6. Dynamically composed resource generation

Description: As in Figure 6, the result of online evaluation is given as score acquired and current expertise level .Based on above parameters it gives only that lists the resources that user is weak at in form of URLs.

Also there is provision for alternative URL's for every category. Instead of collecting all feedback at the end of evaluation, simultaneous feedback is collected from user for resources at each level (range 1-5).Ranking of URI is done the next time another user logs in. Ranking also takes into account the administrator rating; number of users accessed the resources and authenticity of source thus ensuring quality resources available to learners every time

Some of the benefits of the proposed system over existing system are listed in Table 3:

Table 3. Comparison between existing proposed learning based systems

\begin{tabular}{|c|c|}
\hline Proposed System & $\begin{array}{c}\text { Existing web based } \\
\text { Learning System }\end{array}$ \\
\hline $\begin{array}{c}\text { Dynamic knowledge base } \\
\text { presented for each user }\end{array}$ & $\begin{array}{c}\text { Prepackaged knowledge } \\
\text { modules }\end{array}$ \\
\hline Formative assessment & \\
\cline { 1 - 1 } $\begin{array}{c}\text { Ranking of resources for } \\
\text { each category }\end{array}$ & No such provision \\
\cline { 1 - 1 } $\begin{array}{c}\text { Alternative Resources at } \\
\text { all learning levels }\end{array}$ & \\
\hline $\begin{array}{c}\text { Personalized user profile } \\
\text { creation }\end{array}$ & \\
\hline
\end{tabular}

\section{RESULT OF THE DEVELOPED PROTOTYPE}

Several samples of learning results were collected to demonstrate the effectiveness of the proposed prototype. The developers were asked to code a certain module after using the elearning system and their code performance was measured in terms of memory (megabytes) and CPU execution speed (milliseconds).Table 4 clearly indicates a significant improvement in learning abilities before and after usage of E learning system. There is a reduction in amount of memory required and executable lines of code resulting in overall increase in efficiency

Table 4. Learner evaluation before and after Elearning Web Service usage

\begin{tabular}{|c|c|c|c|c|c|c|}
\hline $\begin{array}{c}\text { Sa } \\
\text { mpl } \\
\text { es }\end{array}$ & \multicolumn{2}{|c|}{ Memory } & \multicolumn{2}{c|}{$\begin{array}{c}\text { Execution } \\
\text { Speed }\end{array}$} & \multicolumn{2}{c|}{ ELOC } \\
\hline & $\begin{array}{c}\text { Initial } \\
\text { Value } \\
\text { (MB) }\end{array}$ & $\begin{array}{c}\text { Final } \\
\text { Value } \\
\text { (MB) }\end{array}$ & $\begin{array}{c}\text { Initial } \\
\text { Value } \\
\text { (Ms) }\end{array}$ & $\begin{array}{c}\text { Final } \\
\text { Value } \\
\text { (ms) }\end{array}$ & $\begin{array}{c}\text { Initial } \\
\text { Value }\end{array}$ & $\begin{array}{c}\text { Final } \\
\text { Value }\end{array}$ \\
\hline 1 & 11.1 & 6.2 & 63 & 47 & 122 & 109 \\
\hline 2 & 7 & 5.8 & 31 & 18 & 53 & 51 \\
\hline 3 & 15.6 & 12.3 & 1212 & 1045 & 253 & 174 \\
\hline 4 & 14 & 13.6 & 960 & 751 & 398 & 331 \\
\hline 5 & 12.1 & 11.9 & 88 & 79 & 117 & 120 \\
\hline 6 & 6.3 & 5 & 32 & 24 & 26 & 17 \\
\hline 7 & 13.2 & 12.8 & 355 & 272 & 98 & 86 \\
\hline
\end{tabular}




\begin{tabular}{|c|c|c|c|c|c|c|}
\hline 8 & 8.4 & 7.6 & 128 & 115 & 22 & 19 \\
\hline 9 & 11.6 & 9.8 & 39 & 29 & 135 & 103 \\
\hline 10 & 9.3 & 7.9 & 56 & 43 & 46 & 34 \\
\hline
\end{tabular}

\section{REFERENCES}

[1] http://elinnovations.blogspot.in/2010/02/whatselearning.html.

[2] The Startup Magazine for Business Entreprenuers investing in learning software systems http://thestartupmagazine.co.uk/index.php/globalgrowth-e-learning/

[3] Mingfei Wang, Linlin $\mathrm{Ci}$, Ping Zhan, Yongjun $\mathrm{Xu}$, "Applying Wireless Sensor Networks to ContextAwareness in Ubiquitous Learning", IEEE Third International Conference on Natural Computation (ICNC 2007),2007, Vol. 5, pp. 791-795.

[4] Tzone-I. Wang, Kun-Te Wang, Yueh-Min Huang," Using a style-based ant colony system for adaptive learning" in Elsevier Journal on Expert System with Application, 2008, Vol. 34, No. 4, pp. 244-246.

[5] Yang. S. J. H, "Context Aware Ubiquitous Learning Environment for Peer- to- Peer Collaborative Learning", Educational Technology and Society, Vol. 9, No.1, 2006, pp. 188-201.

[6] Frank Leymann, Francisco Curbera,Web Services: A Realization of SOA,Chapter 3,Pg 31

For corporate sectors, it can lead to faster development of software projects due to reduction in time for appropriate skill acquisition.Currently the framework is implemented using SOAP based services. We are working at extending the proposed framework by including REST based web service and creating service mashup.Certain architecture modules need to be studied in greater depth for more reliable composition.

[7] WSG, (2004). Web Services Glossary. W3C, http://www.w3.org/TR/ws-gloss/

[8] M.P. Singh and M.N. Huhns, Service Oriented Computing,Wiley,2005.

[9] Incheon Paik, Wuhui Chen ,"A Scalable Architecture for Automatic Service Composition" in IEEE Transactions on Service Computing, VOL. 7, NO. 1, January 2014 